\title{
Effects of Volume Fraction and Stability of Retained Austenite on Ductility of TRIP-aided Dual-phase Steels
}

\author{
Koh-ichi SUGIMOTO, Noboru USUI, ${ }^{1)}$ Mitsuyuki KOBAYASHI ${ }^{2)}$ and Shun-ichi HASHIMOTO ${ }^{3)}$
}

Department of Functional Machinery and Mechanics, Shinshu University, Tokida, Ueda, Nagano-ken, 386 Japan.

1) Graduate School, Shinshu University, Tokida, Ueda, Nagano-ken, 386 Japan. Engineering, Shinshu University, Wakasato, Nagano, Nagano-ken, 380 Japan.

Kobe Steel, Ltd., Onoe-cho, Kakogawa, Hyogo-ken, 675 Japan.

2) Department of Mechanical Systems

3) Iron and Steel Research Laboratories,

(Received on July 8, 1992; accepted in final form on September 18, 1992)

The effects of silicon and manganese contents on volume fraction and stability of retained austenite particles in $0.2 \mathrm{C}-(1.0-2.5) \mathrm{Si}-(1.0-2.5) \mathrm{Mn}$ (mass\%) TRIP-aided dual-phase steels were investigated. In addition, the relationships between above retained austenite parameters and ductility at room and moderate temperatures were discussed through studies on strain-induced transformation behavior of retained austenite.

As increasing the silicon and manganese contents except for 2.5 mass $\%$ manganese steel, the initial volume fraction of retained austenite increased with accompanied by reducing carbon concentration in retained austenite. It was found that the ductilities of these steels became maximum at a given temperature between 23 and $175^{\circ} \mathrm{C}$, i.e., a peak temperature. The peak temperature was concluded to agree well with the temperature at which the strain-induced transformation of retained austenite was suppressed moderately for each steel. Moreover, the peak temperature $T p\left({ }^{\circ} \mathrm{C}\right)$ was related to estimated martensite-start temperature $M s\left({ }^{\circ} \mathrm{C}\right)$ of the retained austenite as $T p=3.04 M s+187$. Strength-ductility balance, i.e., the product of tensile strength and total elongation, at the peak temperature linearly increased with an increase in the initial volume fraction of retained austenite.

KEY WORDS: high strength steel; dual phase steel; retained austenite; bainite; transformation induced plasticity; strain induced transformation; ductility; moderate temperature; stability; $M s$ temperature; carbon concentration; manganese; silicon.

\section{Introduction}

Recently, a new type of high strength and high ductility dual phase steel associated with transformation induced plasticity (TRIP) ${ }^{1,2)}$ of retained austenite, i.e., a TRIP-aided dual phase steel, has developed to lighten the weights of various automotive structural press parts. ${ }^{3-11)}$ The microstructure of these steels is composed of ferrite matrix and 20-40 vol\% second phase particles (bainite plus 5-20 vol\% retained austenite). ${ }^{3-11)}$ And, a number of retained austenite particles are isolated in the ferrite matrix and/or along the ferrite grain-boundary, and are away from or adjacent to the bainite particles. Such the retained austenite morphology is effective for transformation induced plasticity compared to retained austenite film along bainitic-ferrite lath. ${ }^{8)}$ Moreover, the retained austenite is carbon-enriched from 1.1 to 1.7 mass $\%^{4-6)}$ and the $M S$ temperature is estimated to be lower than room temperature. ${ }^{6)}$ So, the strain induced transformation influences upon the deformation behavior above room temperature.

The authors have reported using a $0.4 \mathrm{C}-1.5 \mathrm{Si}-$ $1.5 \mathrm{Mn}(\operatorname{mass} \%)$ TRIP-aided dual-phase steel as follows.

(1) The total elongations at the temperatures between 100 and $200^{\circ} \mathrm{C}$, i.e., peak temperature, enhanced up to $40-50 \%$ equivalent to 1.5 times of that at room temperature.

(2) This was concluded to be caused by that the strain induced transformation of retained austenite was suppressed considerably in this moderate temperature range.

Up to now, many workers ${ }^{4,10,11)}$ have reported the effects of chemical composition on ductility for weldable 0.1-0.2C TRIP-aided dual-phase steels. However, these results were restricted within ones at room temperature. Considering the warm forming, we need to examine again the effect of chemical composition on ductility in a moderate temperature range. Moreover, metallurgical factors controlling the ductility must be also investigated in detail.

Such the effects of the warm deformation have expected to be principally connected with retained austenite stability, i.e. carbon and manganese concentration, $M s$ temperature and strain induced transformation behavior. ${ }^{6,7)}$ However, there is little study ${ }^{6)}$ dealing with the ductility from such the point of view. In this study,

(1) the effects of silicon and manganese on retained austenite parameters, i.e., volume fraction, carbon concentration, $M s$ temperature and decomposing tem- 
perature of retained austenite to bainite, were examined using several $0.2 \mathrm{C}-\mathrm{Si}-\mathrm{Mn}$ TRIP-aided dual-phase steels.

(2) And, the relationship between these retained austenite parameters and the ductility (the total elongation and the peak temperature) was investigated through the studies of strain induced transformation behaviors.

\section{Experimental Procedure}

The chemical composition in mass $\%$ of the steels used in this study was shown in Table 1. Steels A-D were $1.5 \mathrm{Si}-(1.0-2.5) \mathrm{Mn}$ steels, while steels $\mathrm{E}-\mathrm{G}$ were $1.5 \mathrm{Mn}-$ $(1.0-2.5) \mathrm{Si}$ steels. These steels were prepared as vacuum-melted $50 \mathrm{~kg}$ ingots followed by hot-forging to produce a $30 \mathrm{~mm}$ thick slab. The slabs were reheated to $1200^{\circ} \mathrm{C}$ and hot-rolled to $3.2 \mathrm{~mm}$ thickness, finishing at $950^{\circ} \mathrm{C}$ and subsequently air-cooling. After cold-rolling the plates to $1.2 \mathrm{~mm}$ thickness, JIS-13B type tensile specimens $(50 \mathrm{~mm}$ gauge length by $12.5 \mathrm{~mm}$ width) were machined parallel to the rolling direction. All the specimens were intercritically annealed at $780-860^{\circ} \mathrm{C}$ for $1000 \mathrm{sec}$ followed by immersing in salt bath at $400^{\circ} \mathrm{C}$ for $1000 \mathrm{sec}$ and then cooling in oil, as shown in Fig. 1. The annealing temperature $T_{1}$ for each steel is shown in Table 1 and corresponds to one at which the initial volume fraction of retained austenite becomes almost maximum. The cooling rate from the intercritical annealing temperature to $400^{\circ} \mathrm{C}$ was nearly $120^{\circ} \mathrm{C} / \mathrm{s}$.

Tensile tests were carried out on a hard-beam tensile testing machine over a temperature range between -50 and $400^{\circ} \mathrm{C}$ and at a mean strain rate of $2.8 \times 10^{-4} / \mathrm{s}$. Each specimen was directly heated using a pair of strip heaters $(70 \mathrm{~mm} \times 90 \mathrm{~mm})$ during tension testing.

The volume fractions of retained austenite were quantified by X-ray diffractometry using the five peak method. ${ }^{12)}$ The lattice parameter of retained austenite $a_{\gamma}\left(10^{-10} \mathrm{~m}\right)$ was also measured using X-ray diffractometry, and from the measured value and the following

Table 1. Chemical composition and intercritical annealing temperature $T_{1}$ of steels used.

\begin{tabular}{c|cccccccc|c}
\hline Steel & $\mathrm{C}$ & $\mathrm{Si}$ & $\mathrm{Mn}$ & $\mathbf{P}$ & $\begin{array}{c}\mathrm{S} \\
(\mathrm{mass} \%)\end{array}$ & $\mathrm{Al}$ & $\mathrm{O}$ & $\mathrm{N}$ & $\begin{array}{c}T_{1} \\
\left({ }^{\circ} \mathrm{C}\right)\end{array}$ \\
\hline $\mathrm{A}$ & 0.21 & 1.51 & 1.00 & 0.015 & 0.0013 & 0.041 & 0.0010 & 0.0017 & 800 \\
$\mathrm{~B}$ & 0.20 & 1.50 & 1.50 & 0.015 & 0.0012 & 0.041 & 0.0010 & 0.0027 & 780 \\
$\mathrm{C}$ & 0.20 & 1.49 & 1.99 & 0.015 & 0.0015 & 0.039 & 0.0020 & 0.0017 & 820 \\
$\mathrm{D}$ & 0.21 & 1.50 & 2.51 & 0.014 & 0.0017 & 0.038 & 0.0009 & 0.0027 & 820 \\
$\mathrm{E}$ & 0.20 & 1.00 & 1.50 & 0.014 & 0.0013 & 0.038 & 0.0010 & 0.0026 & 780 \\
$\mathrm{~F}$ & 0.18 & 2.00 & 1.50 & 0.015 & 0.0013 & 0.037 & 0.0012 & 0.0021 & 820 \\
$\mathrm{G}$ & 0.19 & 2.48 & 1.49 & 0.014 & 0.0013 & 0.036 & 0.0014 & 0.0027 & 860 \\
\hline
\end{tabular}

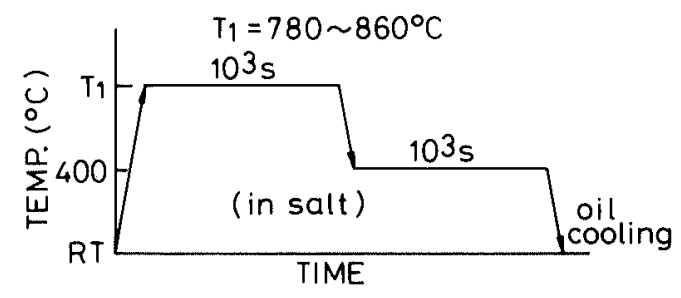

Fig. 1. Heat treatment diagram.
Eq. $(1)^{13)}$ the carbon concentration in retained austenite $c_{\gamma}(\mathrm{mass} \%)$ was calculated.

$$
a_{\gamma}=3.5467+0.0467 c_{\gamma}
$$

where the effect of silicon and manganese concentrations on the lattice parameter was ignored because these effects were much smaller than that of carbon concentration. ${ }^{14)}$

\section{Results}

\subsection{Initial Retained Austenite Parameters}

\subsubsection{Initial Volume Fraction, Carbon Concentration and $M s$ Temperature}

Table 2 shows the volume fractions of second phase $f$ and retained austenite $f_{y 0}$ and carbon concentration $c_{y}$ in retained austenite in heat-treated specimens. And, the typical scanning electron micrographs are shown in Fig. 2.

It is found for all the steels that the second phase islands composed of bainite and retained austenite particles lie along the ferrite grain boundary. The retained austenite particles are isolated from or adjacent to the bainite, so that the strain induced transformation of retained austenite is expected to occur effectively for increasing the ductility. ${ }^{8)}$ The volume fraction of second phase increases with increasing manganese or silicon content, although the effect of silicon is a little compared to that of manganese.

The initial volume fraction of retained austenite increases with increasing the silicon and manganese contents except for $2.5 \% \mathrm{Mn}$ steel (Steel D), and the amounts are in a wide range between 5.8 and 13.7 vol\%. On the other hand, the carbon concentration $c_{\gamma}$ reduces with increase in silicon and manganese contents. The resultant carbon concentration are between 1.13 and 1.53 mass $\%$, which agrees well with ones reported formerly. ${ }^{4-8)} \mathrm{A}$ difference in carbon content between the steels is considered to hardly influence the carbon concentration because the carbon concentration increases by only 0.005 mass $\%$ per 0.01 mass $\%$ carbon content. ${ }^{6)}$ In addition, the carbon concentration in retained austenite appears to be nearly constant over

Table 2. Volume fractions and some parameters of retained austenite in steels intercritically annealed.

\begin{tabular}{|c|c|c|c|c|c|}
\hline Steel & $f$ & $f_{\gamma}$ & $\begin{array}{c}c_{\gamma} \\
(\operatorname{mass} \%)\end{array}$ & $\begin{array}{c}M s \\
\left({ }^{\circ} \mathrm{C}\right)\end{array}$ & $\begin{array}{c}T_{H} \\
\left({ }^{\circ} \mathrm{C}\right)\end{array}$ \\
\hline A & 0.176 & 0.058 & 1.53 & -61 & 340 \\
\hline B & 0.261 & 0.079 & 1.33 & -19 & 380 \\
\hline C & 0.342 & 0.137 & 1.23 & -13 & 390 \\
\hline $\mathrm{D}$ & 0.365 & 0.080 & 1.13 & -7 & 395 \\
\hline $\mathrm{E}$ & 0.264 & 0.076 & 1.36 & -30 & 370 \\
\hline $\mathrm{F}$ & 0.278 & 0.085 & 1.31 & -12 & 390 \\
\hline $\mathrm{G}$ & 0.204 & 0.103 & 1.29 & -4 & 400 \\
\hline$f, f_{\gamma_{0}}:$ & \multicolumn{5}{|c|}{$\begin{array}{l}\text { volume fractions of the second phase and the initial retained } \\
\text { austenite, respectively. }\end{array}$} \\
\hline & \multirow{2}{*}{\multicolumn{5}{|c|}{$\begin{array}{l}\text { carbon concentration in the retained austenite. } \\
\text { estimated martensite-start temperature. }\end{array}$}} \\
\hline$M s$ & & & & & \\
\hline$T_{H}:$ & \multicolumn{5}{|c|}{$\begin{array}{l}\text { decomposition temperature of the retained austenite to } \\
\text { bainite; tempering time }=600 \mathrm{sec} \text {. }\end{array}$} \\
\hline
\end{tabular}



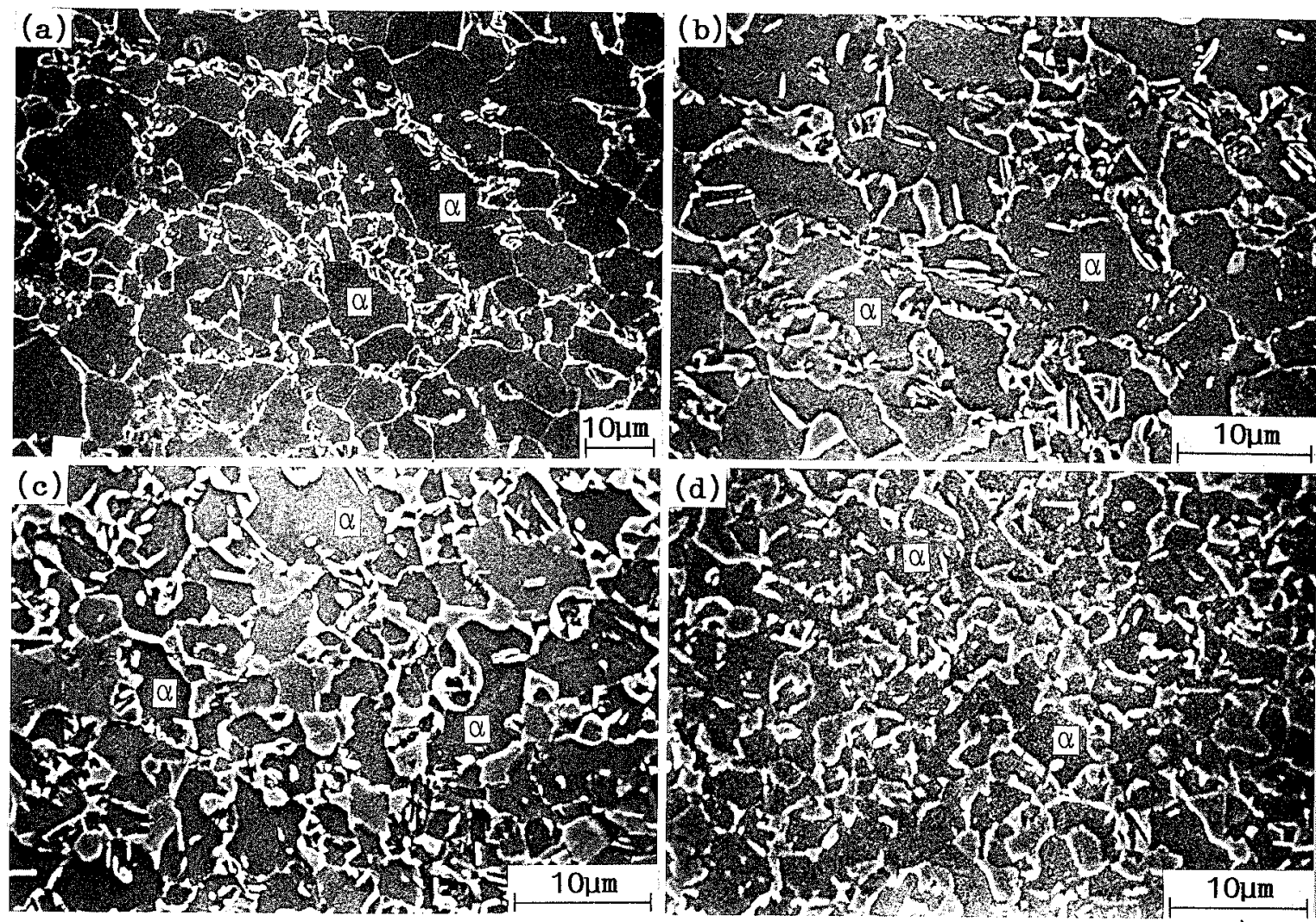

Fig. 2. Typical scanning electron micrographs of (a) steel A, (b) steel B, (c) steel C and (d) steel D, in which $\alpha$ represents ferrite matrix.

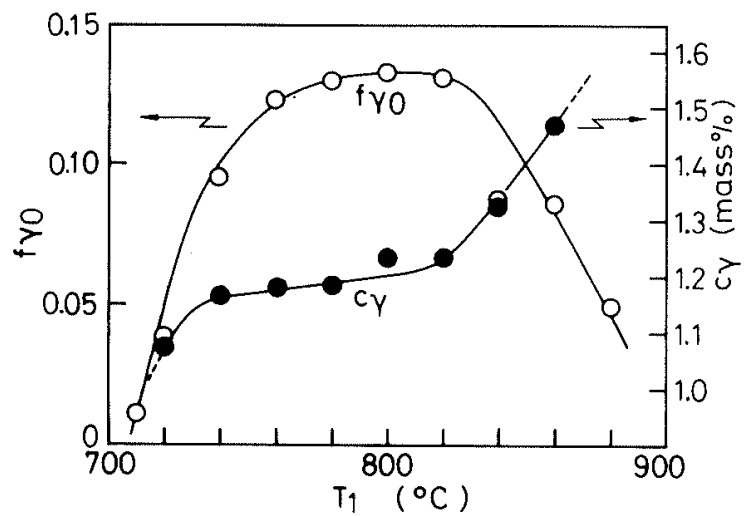

Fig. 3. Initial volume fraction $f_{\gamma_{0}}$ and carbon concentration $c_{\gamma}$ of retained austenite as a function of intercritical annealing temperature $T_{1}$ for steel $\mathrm{C}$.

an intercritical annealing temperature range where the retained austenite content becomes almost maximum, as shown in Fig. 3. Thus, it can be concluded that the carbon concentration shown in Table 2 represents essentially only the effects of manganese and silicon and an influence of the intercritical annealing temperature on it may be ignored. The increase in carbon concentration which occurs at higher annealing temperatures is considered to be ascribed to the appearance of carbon-enriched retained austenite films ${ }^{5,8)}$ along the bainitic-ferrite lath.

Martensite-start temperature $M s\left({ }^{\circ} \mathrm{C}\right)$ of retained austenite can be calculated using the following Eq. (2);

$$
M s=550-(360 \times \% \mathrm{C})-(40 \times \% \mathrm{Mn})
$$

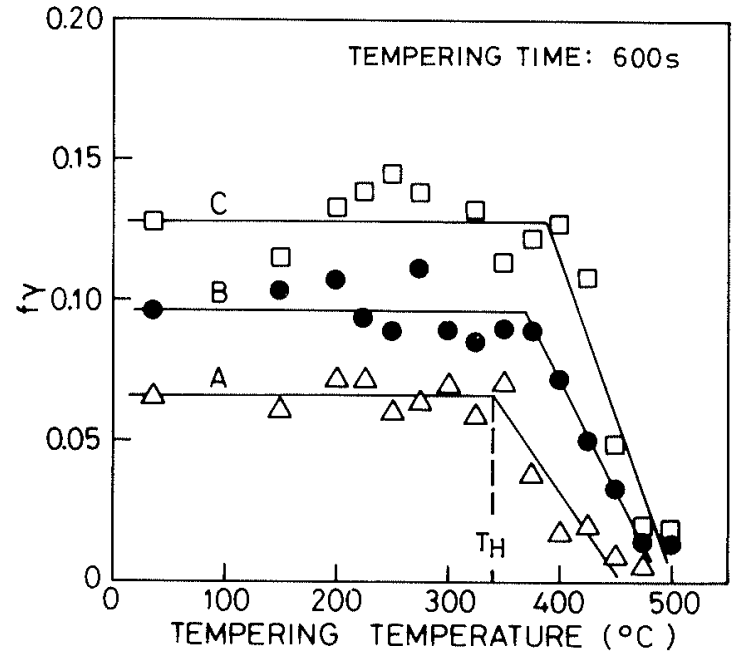

Fig. 4. Variation in volume fraction of retained austenite $f_{y}$ with tempering temperature for steels $\mathrm{A}-\mathrm{C} . T_{H}$ in the figure represents critical temperature at which retained austenite starts to decompose to bainite.

where $\% \mathrm{C}$ and $\% \mathrm{Mn}$ represent carbon and manganese concentrations (mass $\%$ ), respectively. The calculated $M s$ temperatures for the steels are between -4 and $-61^{\circ} \mathrm{C}$ (Table 2), if the manganese concentration is assumed to be 1.5 times of the added content on the basis of useful works of Speich et al. ${ }^{15)}$ and Gilmour et al. ${ }^{16)}$

\subsubsection{Decomposing Temperature to Bainite}

Figure 4 shows the typical variation in retained austenite content with tempering temperature for 600 
sec, which corresponds to tempering time for only heating before tensile testing. The retained austenite is completely stable against the tempering below a given critical temperature $T_{H}$ (Table 2), and above $T_{H}$ the volume fraction decreases drastically. By means of transmission electron microscopy, such the decrease in volume fraction is confirmed to be ascribed to decomposition of retained austenite to bainite.

Figure 5 shows a relationship between $M S$ temperature and $T_{H}$. The figure also contains a result for 3600 sec, which corresponds to tempering time until the completion of tensile test. It is found that the temperature $T_{H}$ increases linearly with increase in the $M s$

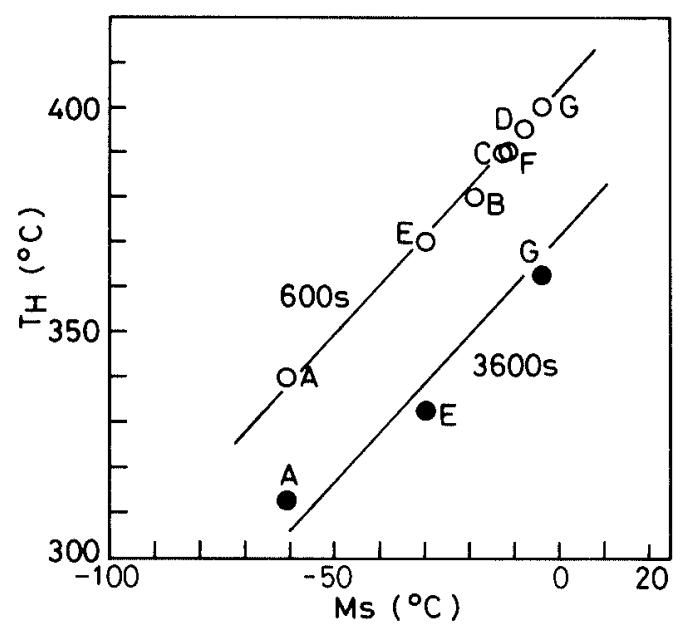

Fig. 5. Relationship between critical decomposition temperature of retained austenite to bainite $T_{H}$ and $M S$ temperature of retained austenite for unstrained steels. Numerals in the figure represent tempering time.

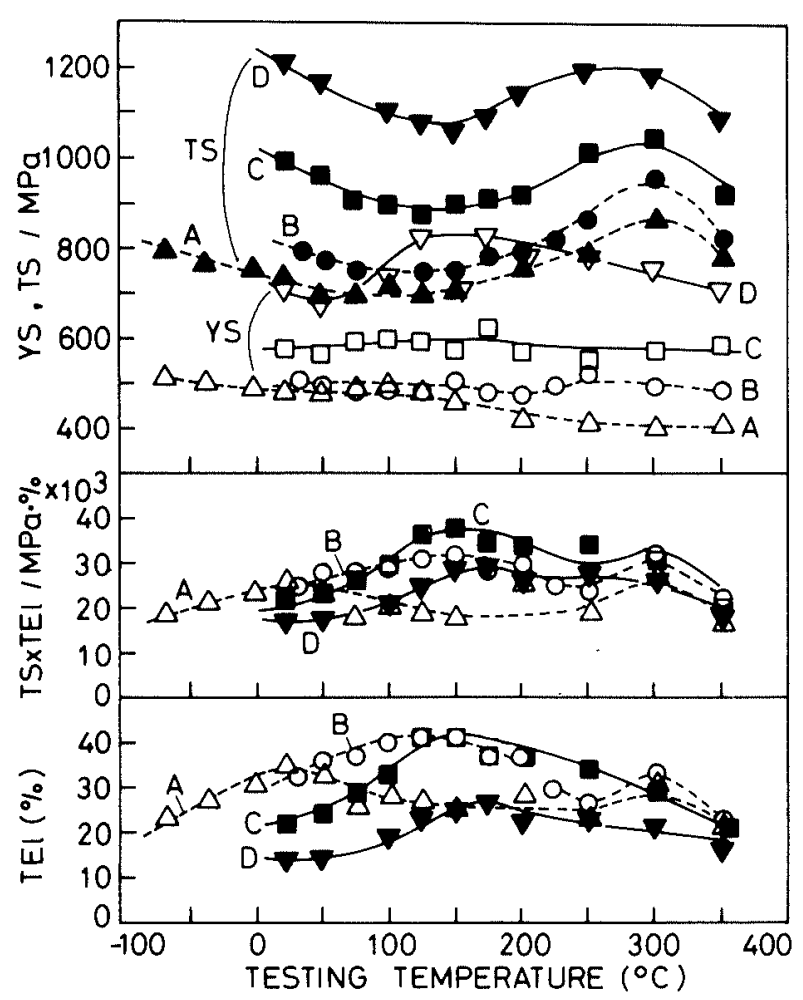

temperature, and for tempering time $=600 \mathrm{sec}$ both the temperatures $\left({ }^{\circ} \mathrm{C}\right)$ are related as the following Eq. (3).

$$
T_{H}=395-M s
$$

3.2. Testing Temperature Dependence of Tensile Properties

Typical nominal stress - strain curve and strain hard-
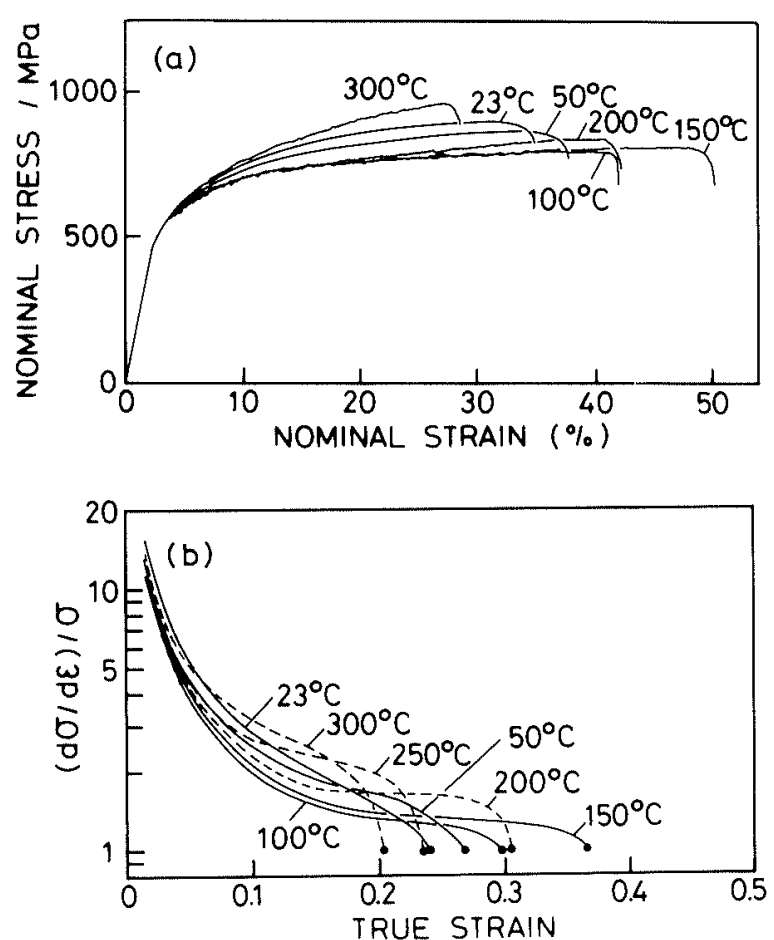

Fig. 6. Changes in flow curve and strain-hardenability $(d \sigma / d \varepsilon) / \sigma$ for steel $F$.

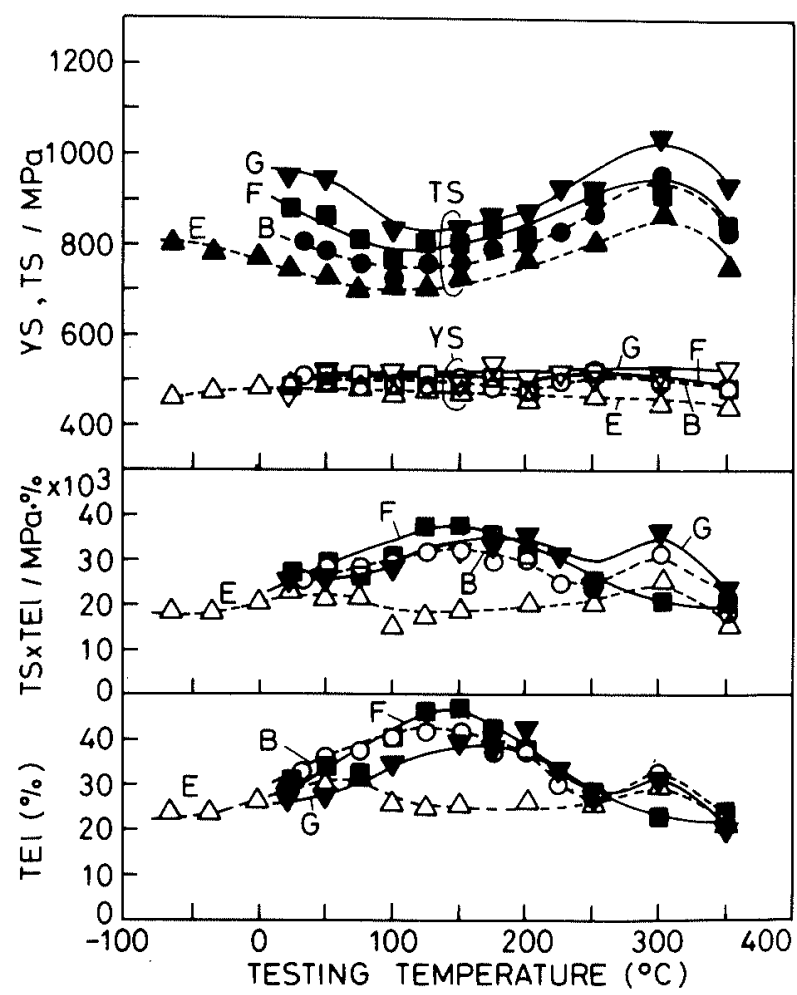

Fig. 7. Testing temperature dependences of tensile strength $T S$, yield stress (or $0.2 \%$ proof stress) $Y S$, total elongation $T E l$ and strength-ductility balance $T S \times T E l$. 
enability $(d \sigma / d \varepsilon) / \sigma(\sigma$ : true stress)-true strain $\varepsilon$ curve are shown in Fig. 6. As the testing temperature dependence of these curves shows the same tendency for all the steels, the deformation characteristic for steel $F$ is mentioned below as a typical example.

The deformation at $23^{\circ} \mathrm{C}$ is characterized by continuous yielding, relatively large strain hardenability in a small strain range and increased total elongation of about $31 \%$ associated with large uniform elongation of about $27 \%$. As increasing the testing temperature, a number of serrations appears on the flow curves due to strain induced transformation of retained austenite. Moreover, the strain hardenability is held above 1.0 in a large strain range prior to onset of necking although it is lowered considerably in a small strain range. As a result, extremely large total elongation up to $47 \%$ is obtained at $100-200^{\circ} \mathrm{C}$ with decrease in tensile strength. While, at $300^{\circ} \mathrm{C}$ the tensile strength increases considerably due to dynamic strain aging ${ }^{6)}$ and the resultant total elongation decreases.

Figure 7 shows the testing temperature dependence of tensile properties for steels $\mathrm{A}-\mathrm{G}$. It is found that the testing temperature dependence of total elongation differed among the steels and the largest total elongation is obtained at a given temperature between 23 and $175^{\circ} \mathrm{C}$, i.e., peak temperature. The peak temperature $T p\left({ }^{\circ} \mathrm{C}\right)$ increases with increase in silicon and manganese contents (namely with decrease in carbon concentration in retained austenite) and is related to $M s$ temperature $M s\left({ }^{\circ} \mathrm{C}\right)$ of retained austenite as the following Eq. (4), as shown in Fig. 8.

$$
T p=3.04 M s+187
$$

The linear relation similar to Eq. (4) is also obtained in

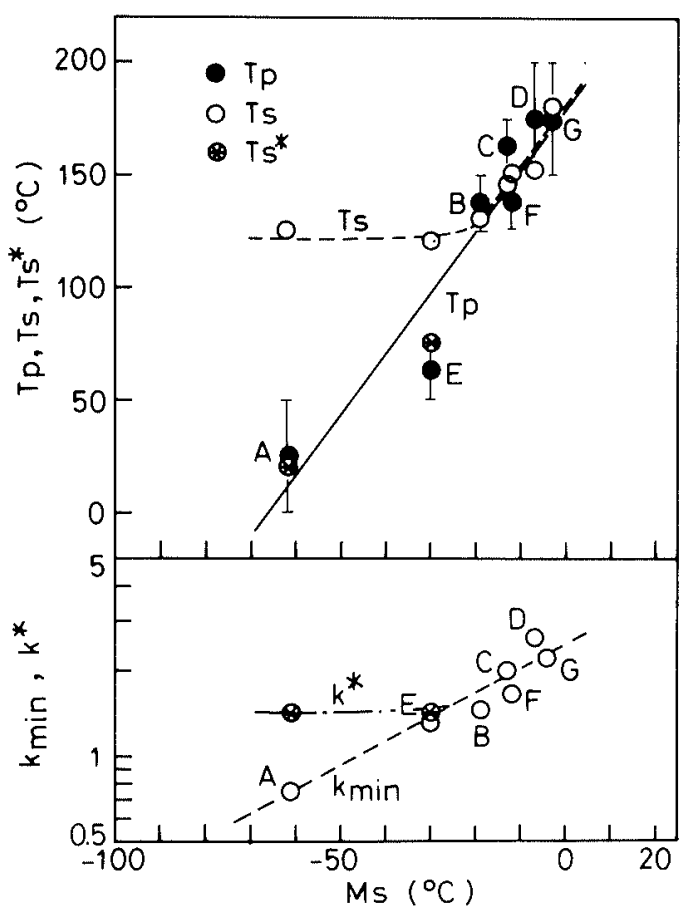

Fig. 8. Variations in peak temperature of total elongation $T p$ and strain induced transformation parameters $T s$, $T s^{*}, k_{\min }$ and $k^{*}$ (which are defined in Figs. 10 and 11; see Sec. 4.2) as a function of $M s$ temperature. a case of manganese concentration being estimated to be 1 to 2 times of the added content. Note that larger total elongation at $23^{\circ} \mathrm{C}$ (room temperature) is obtained in the steel of lower $M S$ temperature because the peak temperature appeares at near $23^{\circ} \mathrm{C}$.

Figure 9 shows a relationship between strength-ductility balance $(T S \times T E l)$ at peak temperature or $23^{\circ} \mathrm{C}$ and initial retained austenite content. The lines in the figure are drawn for steels A-C. The strength-ductility balance at peak temperature is found to increase linearly with increase in the initial retained austenite content. And, since the strength-ductility balance for steels $\mathrm{F}$ and $\mathrm{G}$ shifts upward of the solid line for steels $\mathrm{A}-\mathrm{C}$ the increase in silicon content is concluded to be effective to obtain larger strength-ductility balance. Such the effect of silicon addition was also reported by Sakuma et $a l .{ }^{4)}$ The main reason had been already expected by Davies $^{17)}$ that silicon is preferentially in solute in the ferrite and strengthens the ferrite matrix with some what decrease in the ductility. On the other hand, the strength-ductility balance at $23^{\circ} \mathrm{C}$ unexpectedly reduces with increase in the initial retained austenite content, which shows a different tendency from the results at peak temperature and from some former reports. ${ }^{3,8)}$ As one of this reason it can be considered that the stability against the strain induced transformation at $23^{\circ} \mathrm{C}$ considerably differs among the steels as mentioned latter at Sec 3.3. A sharp fall of strength-ductility balance of steel $\mathrm{D}$ at $23^{\circ} \mathrm{C}$ appears to be ascribed by that the tensile strength increases so much that the total elongation reduces considerably.

Tensile strength is also influenced by testing temperature in the same way as the total elongation, and becomes minimum at a given temperature between 100 and $150^{\circ} \mathrm{C}$, as shown in Fig. 7. Such the temperature is inclined to increase with increase in silicon and manganese contents, namely with increase in $M s$ temperature.

\subsection{Strain Induced Transformation of Retained Aus- tenite}

The authors ${ }^{7)}$ have already reported that retained

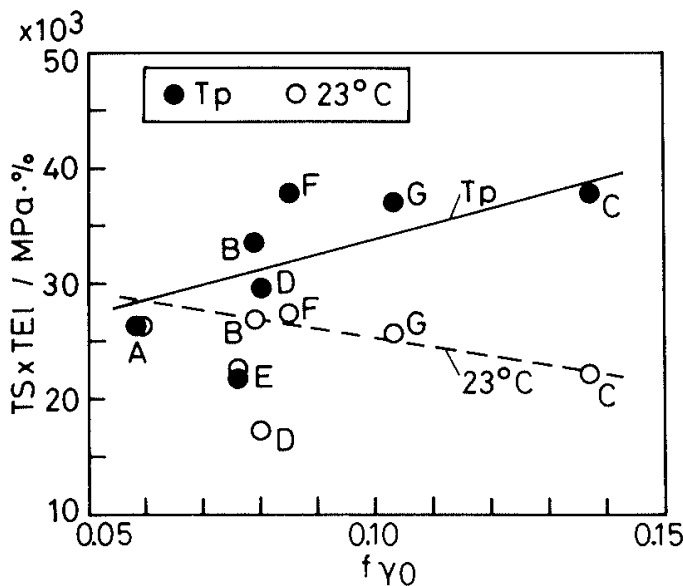

Fig. 9. Relationships between strength-ductility balance $T S \times T E l$ and initial volume fraction of retained austenite $f_{y 0}$ at room temperature $\left(23^{\circ} \mathrm{C}\right)$ and peak temperature $(T p)$, respectively. 


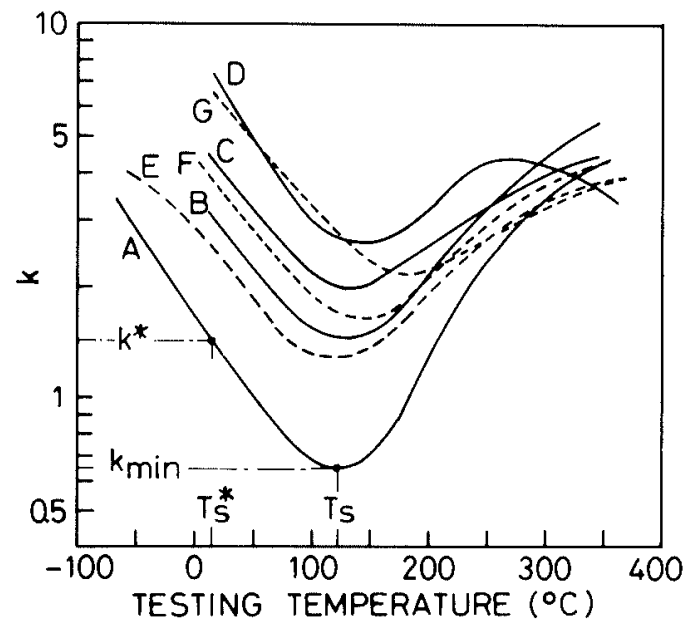

Fig. 10. Variation in $k$-value with testing temperature. $k^{*}$ in the figure is equivalent to $k$-value corresponding to maximum total elongation as shown in Fig. 11.

austenite content $f_{\gamma}$ reduces with an increase in tensile strain $\varepsilon$ as the following Eq. (5);

$$
\log f_{\gamma}=\log f_{\gamma 0}-k \varepsilon
$$

where $k$ is a constant above zero and the value is small when the strain induced transformation of retained austenite is suppressed.

Figure 10 shows a variation in $k$-value with testing temperature. From this figure and Fig. 8, the results are summarized as follows.

(1) $k$-value becomes minimum at temperatures between 100 and $200^{\circ} \mathrm{C}$ for all the steels.

(2) The minimum value $k_{\min }$ linearly reduces with decrease in $M S$ temperature of retained austenite.

(3) The temperature corresponding to $k_{\min }, T s$, decreases with decrease in the $M s$ temperature when $M s>-20^{\circ} \mathrm{C}$, while it is nearly constant (about $120^{\circ} \mathrm{C}$ ) when $M s<-20^{\circ} \mathrm{C}$.

A reason why the temperature $T s$ varies with $M s$ temperature is considered as follows. From Fig. 5, the critical temperature $T_{H}$, at which the retained austenite particles in unstrained samples started to decompose to bainite, increased with increase in $M s$ temperature of retained austenite. Moreover, according to our work ${ }^{7)}$ using a $0.4 \mathrm{C}-1.5 \mathrm{Si}-1.5 \mathrm{Mn}$ (mass \%) TRIP-aided dualphase steel the strain induced bainite transformation occurred preferentially instead of the strain induced martensite transformation above $200^{\circ} \mathrm{C}$. From these experimental facts, the temperature $T s$ is considered to increase with increase in the temperature at which the strain induced bainite transformation of retained austenite starts. In a case of $M s<-20^{\circ} \mathrm{C}$ at which the temperature $T s$ is held constantly, it is estimated that there is a critical temperature below which the strain induced bainite transformation hardly occurs.

\section{Discussion}

4.1. Effects of Silicon and Manganese on Volume Fraction and Carbon Concentration of Retained Austenite

Takahashi and Bhadeshia ${ }^{18)}$ have proposed for car- bide-free bainitic steels that the carbon concentration in retained austenite is equal to one in austenite at $T_{0}$ temperature, where austenite and ferrite of the same chemical composition have identical free energies. According to their theory, manganese addition may lower $A_{e 3}$ and $T_{0}$ temperatures, so that the carbon concentration in austenite at $T_{0}$ temperature reduces relatively although the volume fraction of austenite phase increases.

The above-mentioned theory may explain cleverly the present experimental results that the carbon concentration in retained austenite reduces with increasing the manganese content except for 2.5 mass $\% \mathrm{Mn}$ steel (steel D). The exceptional result for steel $\mathrm{D}$ could be considered as follows. An excess adding of manganese lowers so much the carbon concentration in austenite at $T_{0}$ temperature $^{18)}$ that the bainite transformation starts preferentially prior to formation of carbonenriched austenite on austempering treatment. Thus, the volume fraction of bainite increases considerably resulting in the decreases in volume fraction and carbon conentration of retained austenite.

If retained austenite films are situated along bainiticferrite lath boundary, the carbon concentration increases in spite of decrease in carbon concentration of austenite in $\alpha+\gamma$ region, as mentioned at Sec. 3.1.1. Thus, the theory proposed by Takahashi and Bhadeshia ${ }^{18)}$ may be applied in a case of a moderate annealing temperature at which carbon-enriched and isolated retained austenite particles lie in the ferrite.

It is impossible to apply the above-mentioned theory to explaining the effect of silicon on the retained austenite parameters because the silicon hardly influences $T_{0}$ temperature. Generally, silicon affects scarcely carbon concentration in retained austenite particles in the same manner as aluminum and chromium although it suppresses a carbide precipitation and enhances the volume fraction of retained austenite. ${ }^{5)}$ The total carbon concentrations $f_{y 0} \times c_{\gamma}$ in the retained austenite for steels $\mathrm{E}, \mathrm{B}, \mathrm{F}$ and $\mathrm{G}$ are calculated to be $0.103,0.106$, 0.111 and 0.133 from Table 2, respectively. Thus, the decrease in carbon concentration of retained austenite due to the silicon addition can be considered to be caused by the increase in retained austenite content.

\subsection{Relationship between Peak Temperature and Re- tained Austenite Stability}

Total elongation of TRIP-aided dual phase steels has reported to be mainly controlled by the strain induced transformation behavior of retained austenite. ${ }^{7)}$ So, in this section an essential reltionship between the peak temperature of total elongation and the retained austenite stability is discussed through the results of the strain induced transformation behavior mentioned in the Sec. 3.3.

From Fig. 8, the peak temperature $T p$ is related to the temperature $T s$ as follows;

(1) when $M s>-20^{\circ} \mathrm{C}$, the peak temperature roughly agrees with the temperature $T s$, at which the strain induced transformation of retained austenite is suppressed the most. 


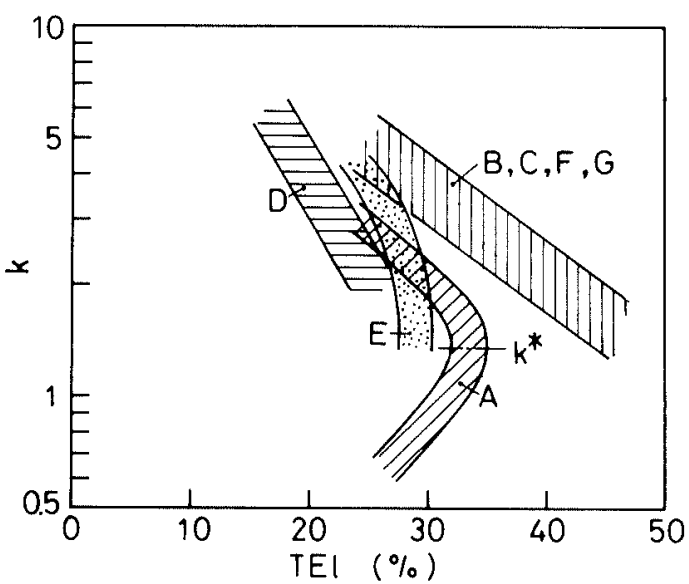

Fig. 11. Relationship between $k$-value and total elongation TEl.

(2) On the other hand, the peak temperature is much lower than $T s$ when $M s<-20^{\circ} \mathrm{C}$.

For explaining these results, a relationship between $k$-value and total elongation, as shown in Fig. 11, was investigated.

From Fig. 11, the total elongation in the steels of $M s>-20^{\circ} \mathrm{C}$ (steels B, C, F and G) is found to increase as the $k$-value decreases, namely as the strain induced transformation is suppressed. In the steels of $M s<$ $-20^{\circ} \mathrm{C}$ (steels $\mathrm{A}$ and $\mathrm{E}$ ), however, the linear relationship between the $k$-value and the total elongation can not be recognized, and the total elongation reduced with decreasing the $k$-value in a opposite way when $k<k^{*}$.

According to a study ${ }^{2)}$ of metastable austenitic TRIP steels, the strain induced transformation of austenite to martensite was suppressed with increasing the testing temperature more than $M s$ temperature, and the austenite became completely stable above $M_{d}$. In addition, the maximum total elongation was obtained at a given temperature between $M s$ and $M_{d}$, at which the strain induced transformation was suppressed moderately and the resultant strain hardenability was held some what higher value than 1.0 in a large strain range. The results obtaind for steels $\mathrm{A}$ and $\mathrm{E}$ seem to be similar to that of TRIP steels. ${ }^{2)}$ Thus, even in the present TRIPaided dual-phase steels it is concluded as follows. Excess increase in retained austenite stability do not always lead to the enhancement of total elongition. Moreover, the maximum total elongation appears at the temperature at which the strain induced transformation is moderately suppressed. An exceptional result for steel $\mathrm{D}$ may be caused by the extremely higher tensile strength.

For steels $\mathrm{A}$ and $\mathrm{E}$, if $k$-value corresponding to maximum total elongation is defined to be $k^{*}$, the temperature $T S^{*}\left(<T S\right.$ ) corresponding to the $k^{*}$ agrees roughly with the peak temperature as a matter of course, as shown in Fig. 8. In the steels except for steels A and $\mathrm{E}$, it is considered that the peak temperature unexpectedly agreed with the temperature $T s$ because the $k_{\min }$ was not too smaller.

In this study, tensile strength became minimum in a temperature range between 100 and $150^{\circ} \mathrm{C}$, and the minimum temperature increased with increasing silicon and manganese contents (i.e. increase in $M s$ temperature of retained austenite) as shown in Fig. 7. Since the minimum temperature agrees nearly with the temperature $T s$ as shown in Figs. 7 and 10, the minimum tensile strength for each steel can be considered to be obtained at the temperature where the strain induced transformation is suppressed the most.

\section{Conclusions}

The effects of silicon and manganese contents on volume fraction and stability of retained austenite in $0.2 \mathrm{C}-(1.0-2.5) \mathrm{Si}-(1.0-2.5) \mathrm{Mn}(\mathrm{mass} \%)$ TRIP-aided dualphase steels were investigated. In addition, the relationships between retained austenite parameters and ductility (i.e., total elongation and the peak temperature) were discussed. The results were summarized as follows.

(1) Manganese addition in the steels increased initial retained austenite content with reducing the carbon concentration of retained austenite, i.e., increase in the $M s$ temperature. The decrease in carbon concentration was explained to be caused by that the manganese reduced $T_{0}$ temperature. Silicon addition apparently brought out a similar effect to manganese one although the effect was smaller than manganese one and essentially differed from the manganese one.

(2) The peak temperature $T p$ of total elongation linearly reduced with decreasing $M S$ temperature of retained austenite, as $T p\left({ }^{\circ} \mathrm{C}\right)=3.04 M s\left({ }^{\circ} \mathrm{C}\right)+187$. On the other hand, the strength-ductility balance at the peak temperature increased with increase in the initial retained austenite content.

(3) The $k$-value which was adopted as a parameter representing strain induced transformation behavior became minimum in a temperature range between 100 and $200^{\circ} \mathrm{C}$. The minmum value $k_{\min }$, at which the strain induced transformation suppressed the most, reduced with decrease in the $M s$ temperature. On the other hand, the temperature corresponding to $k_{\min }, T s$, decreased linearly with decrease in the $M s$ temperature when $M s>-20^{\circ} \mathrm{C}$, while it was constant (about $120^{\circ} \mathrm{C}$ ) when $M s<-20^{\circ} \mathrm{C}$

(4) The peak temperature of total elongation roughly agreed with the temperature $T s$ when $M s>$ $-20^{\circ} \mathrm{C}$, while when $M s<-20^{\circ} \mathrm{C}$ it did with the temperature $T s^{*}$ (at which the strain induced transformation was moderately suppressed).

\section{Acknowledgment}

The authors wish to thank The Amada Foundation for Metal Work Technology for their financial support.

\section{REFERENCES}

1) V. F. Zackay, E. R. Parker, D. Fahr and R. Bush: Trans. Am Soc., 60 (1967), 252

2) I. Tamura, T. Maki and H. Hato: Trans. Iron Steel Inst. Jpn., 10 (1970), 163.

3) O. Matsumura, Y. Sakuma and H. Takechi: Trans. Iron Steel Inst. Jpn., 27 (1987), 570.

4) Y. Sakuma, O. Matsumura and H. Takechi: Metall. Trans. A, 22A (1991), 489. 
5) O. Matsumura, Y. Sakuma and H. Takechi: Tetsu-to-Hagané, 77 (1991), 1304.

6) K. Sugimoto, M. Kobayashi and S. Hashimoto: J. Jpn. Inst. Met., 54 (1990), 657.

7) K. Sugimoto, M. Kobayashi and S. Hashimoto: Metall. Trans. $A$, in press.

8) K. Sugimoto, M. Misu, M. Kobayashi and S. Hashimoto: Tetsu-to-Hagané, 76 (1990), 1356.

9) S. Yasuki, K. Sugimoto, M. Kobayashi and S. Hashimoto: $J$. Jpn. Inst. Met., 54 (1990), 1350.

10) H. C. Chen, E. Era and M. Shimizu: Metall. Trans. A, 20A (1989), 437.

I1) I. Tsukatani and S. Hashimoto: CAMP-ISIJ, 2 (1989), 1827.
12) H. Maruyama: J. Jpn. Soc. Heat Treat., 17 (1977), 198.

13) Z. Nishiyama: Martensite Transformation, Maruzen, Tokyo, (1979), 13.

14) K. J. Irvine, D. T. Llewellyn, and F. B. Pickering: J. Iron. Steel Inst., 199 (1961), 153.

15) G. R. Speich, V. A. Demarest and R. L. Miller: Metall. Trans. A, 12A (1981), 1419.

16) J. B. Gilmour, G. R. Purdy and J. S. Kirkaldy: Metall. Trans., 3 (1972), 1455.

17) R. G. Davies: Metall. Trans. A, 9A (1978), 41.

18) M. Takahashi and Bhadeshia: Trans. Jpn. Inst. Met., 32 (1991), 689. 